Matematikai Közlemények

VI. kötet, 2018

doi:10.20312/dim.2018.03

\title{
Az általánosított kvaternióalgebrák egy új felépítéséről
}

\author{
Péntek Kálmán \\ ELTE SEK TTMK Savaria Matematikai Tanszék \\ pentek.kalman@sek.elte.hu
}

\begin{abstract}
ÖSSZEFOGLALÓ. Hamilton 1843-ban dolgozta ki a valós kvaterniók algebráját, amely lehetőséget nyújt térgeometriai problémák vizsgálatára. Dickson 1912-ben bevezette a test feletti általánosított kvaternió algebrák fogalmát. Ezek struktúráit vizsgálva bevezetjük a szimmetrikus általánosított kvaternió algebrákat és megvizsgáljuk e struktúrák egy érdekes típusát.
\end{abstract}

\begin{abstract}
Hamilton worked out the real quaternion algebra theory in 1843, that enables us to examine problems of spatial geometry. Dickson introduced the generalised quaternion algebras over local fields. Based on their structures, we introduce the symmetrical generalised quaternion algebras and examine an interesting type of them.
\end{abstract}

\section{Bevezetés}

A klasszikus komplex számok algebrájának rendezett valós számpárokból történő felépítését 1833-ban publikálta Sir William Rowan Hamilton (1805-1865) ír matematikus, fizikus és csillagász. Mivel a komplex számok eredményesen használhatók síkgeometriai problémák megoldására, ezért Hamilton a térgeometriai problémák analóg kezelésére a rendezett valós számhármasok algebrájának megalkotását tűzte ki célul. 1843-ban ismerte fel, hogy rendezett valós számhármasok helyett rendezett valós számnégyesekkel érhet célt és megalkotta a valós kvaterniók algebráját. A kvaterniókhoz sokban hasonló split kvaterniók struktúráját 1849-ben az angol Sir James Cockle (1819-1895) dolgozta ki. (HAMILTON 1834, 1844)

Leonard Eugene Dickson (1874-1954) 1912-ben bevezette a test feletti általánosított kvaternió algebra fogalmát és 1919-ben megalkotta a később Cayley-Dickson-féle megkettőzési eljárásnak nevezett módszert, amellyel Hamilton-féle kvaterniókból kiindulva felépítette a Cayley-féle oktoniók struktúráját. (ROSENFELD 1997, WARD 1997)

Ebben a dolgozatban a Cayley-Dickson-féle eljárás egy általánosítását alkalmazva a valós számok $\mathbb{R}$ struktúrájából elindulva először az általánosított komplex számok $\mathbb{C}_{\alpha}$ struktúráját, ebböl pedig ezután az általánosított kvaterniók $\mathbb{H}_{\alpha \beta}$ struktúráját építjük fel.

\section{Az általánosított komplex számok}

Jelölje $\{\mathbb{R},+, \cdot\}$ a valós számok testét és értelmezzünk müveleteket az

$$
\mathbb{R} \times \mathbb{R}:=\{(a, b): a, b \in \mathbb{R}\}
$$

KULCSSZAVAK. Általánosított komplex számok, általánosított kvaterniók, hiperkomplex számok, Cayley-Dickson eljárás

KeYwordS. Generalized Complex Numbers, Generalized Quaternions, Hypercomplex Numbers, Cayley-Dickson Process. 
direktszorzatban az alábbi módon:

$$
\begin{array}{llrl} 
& \text { skalárral való szorzás: } r \cdot(a, b) & := & (r \cdot a, r \cdot b), \\
& \text { összeadás: } & (a, b)+(c, d): & :=(a+c, b+d), \\
& \text { szorzás: } & (a, b) \cdot(c, d): & :=(a \cdot c-\alpha \cdot b \cdot d, a \cdot d+b \cdot c),
\end{array}
$$

ahol $r \in \mathbb{R},(a, b),(c, d) \in \mathbb{R} \times \mathbb{R}$ tetszőlegesek, továbbá $\alpha \in \mathbb{R}$ egy rögzített valós paraméter.

Egyszerü közvetlen számolással igazolhatjuk, hogy $\mathbb{R} \times \mathbb{R}$ az (1),(2) és (3) müveletekkel egy 2-dimenziós kommutatív, asszociatív és neutrális elemes algebrát alkot az $\mathbb{R}$ test felett. $\mathrm{E}$ struktúra összeadási neutrális eleme a $\mathbf{0}:=(0,0)$, szorzási neutrális eleme az $\mathbf{1}:=(1,0)$, továbbá mint $\mathbb{R}$ feletti vektortérben az $\mathbf{1}:=(1,0)$ és az $\boldsymbol{i}:=(0,1)$ egy természetes bázist alkot.

Az $S:=\{(a, 0): a \in \mathbb{R}\} \subset \mathbb{R} \times \mathbb{R}$ halmazról könnyen beláthatjuk, hogy zárt az (1), (2) és (3) müveletekre, továbbá az $f: \mathbb{R} \rightarrow \mathrm{S}, a \mapsto(a, 0)$ leképezésröl megmutathatjuk, hogy egy algebra-izomorfizmus, amelynek alapján az $f^{*}: \mathbb{R} \rightarrow \mathbb{R} \times \mathbb{R}, a \mapsto(a, 0)$ algebramonomorfizmussal $\mathbb{R}$ beleágyazható az $\mathbb{R} \times \mathbb{R}$ algebrába.

A beágyazás eredményeként nyert struktúrát az általánosított komplex számok algebrájának nevezzük és a $\mathbb{C}_{\alpha}$ szimbólummal jelöljük. Speciálisan, ha $\alpha=1$, akkor a klasszikus Gauss-féle komplex számok $\mathbb{C}$, ha $\alpha=0$, akkor a duális komplex számok $\mathbb{C}^{\circ}$, $\mathrm{s}$ ha $\alpha=-1$, akkor a split komplex számok $\mathbb{C}^{\prime}$ algebrájához juthatunk el. Bizonyítható, hogy minden $\mathbb{R}$ feletti 2-dimenziós asszociatív algebra izomorf az $\alpha \in \mathbb{R}$ paraméter 1,0, vagy -1 értékéhez tartozó $\mathbb{C}_{\alpha}$ struktúra valamelyikével.

Az $\boldsymbol{i}=(0,1) \in \mathbb{C}_{\alpha}$ elemröl megmutatható, hogy (a) $\boldsymbol{i}^{2}=-\alpha$, (b) $(0, b)=b \cdot \boldsymbol{i}$, (c) minden $(a, b) \in \mathbb{C}_{\alpha}$ felírható $a+b \cdot \boldsymbol{i}$ alakban, amelyet az általánosított komplex szám algebrai alakjának nevezünk. Az általánosított komplex számok algebrai alakjával a következő számolási szabályok szerint dolgozhatunk:

$$
\begin{aligned}
r \cdot(a+b \cdot \boldsymbol{i}) & =(r \cdot a)+(r \cdot b) \cdot \boldsymbol{i}, \\
(a+b \cdot \boldsymbol{i})+(c+d \cdot \boldsymbol{i}) & =(a+c)+(b+d) \cdot \boldsymbol{i}, \\
(a+b \cdot \boldsymbol{i}) \cdot(c+d \cdot \boldsymbol{i}) & =(a \cdot c-\alpha \cdot b \cdot d)+(a \cdot d+b \cdot c) \cdot \boldsymbol{i},
\end{aligned}
$$

ahol $r \in \mathbb{R}$ és $a+b \cdot \boldsymbol{i}, c+d \cdot \boldsymbol{i} \in \mathbb{C}_{\alpha}$ tetszöleges elemek.

A $z=a+b \cdot i \in \mathbb{C}_{\alpha}$ konjugáltján a $\bar{z}=a-b \cdot i \in \mathbb{C}_{\alpha}$ számot értjük. A konjugálást az alábbi tulajdonságok jellemzik: (a) $\overline{\bar{z}}=z$ involutív, (b) $\overline{r \cdot z}=r \cdot \bar{z}$ homogén, (c) $\overline{z+t}=\bar{z}+\bar{t}$ additív, (d) $\overline{z \cdot t}=\bar{z} \cdot \bar{t}$ multiplikatív, (e) $z \cdot \bar{z}=\bar{z} \cdot z=a^{2}+\alpha \cdot b^{2} \in \mathbb{R}$ teljesül, ahol $r \in \mathbb{R}, z, t \in \mathbb{C}_{\alpha}$.

A $z=a+b \cdot \boldsymbol{i} \in \mathbb{C}_{\alpha}$ normáján az $N(z):=z \cdot \bar{z} \in \mathbb{R}$ valós számot értjük, amelyre teljesülnek a következő összefüggések: (a) minden $z, t \in \mathbb{C}_{\alpha}$ esetén $N(z \cdot t)=N(z) \cdot N(t)$, (b) a $z \in \mathbb{C}_{\alpha}$ invertálható akkor és csakis akkor, ha $N(z) \neq 0$, (c) ha $z, t \in \mathbb{C}_{\alpha}$ invertálható elemek, akkor a $z \cdot t \in \mathbb{C}_{\alpha}$ is invertálható és $(z \cdot t)^{-1}=z^{-1} \cdot t^{-1}$.

A $z=a+b \cdot \boldsymbol{i}, t=c+d \cdot \boldsymbol{i} \in \mathbb{C}_{\alpha}$ elempár skaláris szorzatán a $\langle z, t\rangle:=a \cdot c+\alpha \cdot b \cdot d$ valós számot értjük. A skaláris szorzat egy szimmetrikus bilineáris leképezés, amelyből a norma az $N(z)=\langle z, z\rangle$ alapján származtatható.

A $z=a+b \cdot \boldsymbol{i} \in \mathbb{C}_{\alpha}$ általánosított komplex számok reprezentálhatók az

$$
A=\left(\begin{array}{cc}
a & b \\
-\alpha \cdot b & a
\end{array}\right) \in M_{2}(\mathbb{R})
$$

alakú másodrendủ négyzetes mátrixok $M_{2}^{\mathbb{C}}(\mathbb{R})$ halmazával, mert a

$$
g: \mathbb{C}_{\alpha} \rightarrow M_{2}^{\mathbb{C}}(\mathbb{R}), a+b \cdot \boldsymbol{i} \mapsto\left(\begin{array}{cc}
a & b \\
-\alpha \cdot b & a
\end{array}\right)
$$


leképezés egy algebra-izomorfizmus, továbbá érvényes az

$$
N(z)=\operatorname{det}\left(\begin{array}{cc}
a & b \\
-\alpha \cdot b & a
\end{array}\right)
$$

összefüggés.

\section{Az általánosított kvaterniók}

Az általánosított komplex számok $\mathbb{C}_{\alpha}$ 2-dimenziós kommutatív és asszociatív algebrájából kiindulva a $\mathbb{C}_{\alpha} \times \mathbb{C}_{\alpha}:=\left\{\left(z_{1}, z_{2}\right): z_{1}, z_{2} \in \mathbb{C}_{\alpha}\right\}$ direktszorzatban müveleteket értelmezünk az alábbi módon:

$$
\begin{aligned}
& \text { skalárral való szorzás: } r \cdot\left(z_{1}, z_{2}\right):=\left(r \cdot z_{1}, r \cdot z_{2}\right), \\
& \text { összeadás: } \quad\left(z_{1}, z_{2}\right)+\left(w_{1}, w_{2}\right):=\left(z_{1}+w_{1}, z_{2}+w_{2}\right), \\
& \text { szorzás: }\left(z_{1}, z_{2}\right) \cdot\left(w_{1}, w_{2}\right):=\left(z_{1} \cdot w_{1}-\beta \cdot z_{2} \cdot \overline{w_{2}}, z_{1} \cdot w_{2}+z_{2} \cdot \overline{w_{1}}\right),
\end{aligned}
$$

ahol $r \in \mathbb{R},\left(z_{1}, z_{2}\right),\left(w_{1}, w_{2}\right) \in \mathbb{C}_{\alpha} \times \mathbb{C}_{\alpha}$ tetszölegesek, továbbá $\beta \in \mathbb{R}$ egy rögzített valós paraméter.

Egyszerü, bár hosszadalmas számítással beláthatjuk, $\mathbb{C}_{\alpha} \times \mathbb{C}_{\alpha}$ a (10), (11) és (12) müveletekkel egy 4-dimenziós, nem kommutatív, de asszociatív és neutrális elemes algebrát alkot az $\mathbb{R}$ test felett. $\mathrm{E}$ struktúrában az összeadás neutrális eleme a $(\mathbf{0}, \mathbf{0})=(0+0 \cdot \boldsymbol{i}, 0+0 \cdot \boldsymbol{i})$, a szorzás neutrális eleme $(\mathbf{1}, \mathbf{0})=(1+0 \cdot \boldsymbol{i}, 0+0 \cdot \boldsymbol{i})$, továbbá mint $\mathbb{R}$ feletti vektortérben az

$$
\begin{array}{rlrl}
(\mathbf{1}, \mathbf{0}) & =(1+0 \cdot \boldsymbol{i}, 0+0 \cdot \boldsymbol{i}), & & (\boldsymbol{i}, \mathbf{0})=(0+1 \cdot \boldsymbol{i}, 0+0 \cdot \boldsymbol{i}), \\
\boldsymbol{j}:=(\mathbf{0}, \mathbf{1})=(0+0 \cdot \boldsymbol{i}, 1+0 \cdot \boldsymbol{i}), & & (\mathbf{0}, \boldsymbol{i})=(0+0 \cdot \boldsymbol{i}, 0+1 \cdot \boldsymbol{i}) .
\end{array}
$$

elemek egy természetes bázist alkotnak.

A $T:=\left\{\left(z_{1}, \mathbf{0}\right): z_{1} \in \mathbb{C}_{\alpha}\right\} \subseteq \mathbb{C}_{\alpha} \times \mathbb{C}_{\alpha}$ halmaz zárt a (10), (11) és (12) müveletekre, az $F: \mathbb{C}_{\alpha} \rightarrow T, z_{1} \mapsto\left(z_{1}, \mathbf{0}\right)$ leképezés egy algebra-izomorfizmus, ez alapján az $F^{*}: \mathbb{C}_{\alpha} \rightarrow \mathbb{C}_{\alpha} \times \mathbb{C}_{\alpha}, z_{1} \mapsto\left(z_{1}, \mathbf{0}\right)$ egy algebra-monomorfizmus, amellyel a $\mathbb{C}_{\alpha}$ beleágyazható a $\mathbb{C}_{\alpha} \times \mathbb{C}_{\alpha}$ algebrába.

A beágyazás eredményeként nyert struktúrát a továbbiakban általánosított kvaterniók algebrájának nevezzük és a $\mathbb{H}_{\alpha \beta}$ szimbólummal jelöljük. Speciálisan, ha $(\alpha, \beta)=(1,1)$ akkor a klasszikus Hamilton-féle kvaterniók $\mathbb{H}$, ha $(\alpha, \beta)=(1,-1)$, akkor a split kvaterniók $\mathbb{H}^{\prime}$, ha $(\alpha, \beta)=(1,0)$, a szemi kvaterniók $\mathbb{H}^{\circ}$, ha $(\alpha, \beta)=(-1,0)$, akkor a split szemi kvaterniók $\mathbb{H}^{\prime \circ}$, végül ha $(\alpha, \beta)=(0,0)$, akkor a kvázi kvaterniók $\mathbb{H}^{\circ \circ}$ algebráját kapjuk.

A $\boldsymbol{j}=(\mathbf{0}, \mathbf{1}) \in \mathbb{H}_{\alpha \beta}$ elemröl megmutatható, hogy (a) $\boldsymbol{j}^{2}=-\beta$, (b) $\left(0, z_{2}\right)=z_{2} \cdot \boldsymbol{j}$, (c) minden $\left(z_{1}, z_{2}\right) \in \mathbb{H}_{\alpha \beta}$ felírható $z_{1}+z_{2} \cdot \boldsymbol{j}$ alakban, amelyet az általánosított kvaternió komplex algebrai alakjának nevezzük. Az általánosított kvaterniók komplex algebrai alakjával a következő szabályok szerint dolgozhatunk:

$$
\begin{aligned}
r \cdot\left(z_{1}+z_{2} \cdot \boldsymbol{j}\right) & =\left(r \cdot z_{1}\right)+\left(r \cdot z_{2}\right) \cdot \boldsymbol{j} \\
\left(z_{1}+z_{2} \cdot \boldsymbol{j}\right)+\left(w_{1}+w_{2} \cdot \boldsymbol{j}\right) & =\left(z_{1}+w_{1}\right)+\left(z_{2}+w_{2}\right) \cdot \boldsymbol{j} \\
\left(z_{1}+z_{2} \cdot \boldsymbol{j}\right) \cdot\left(w_{1}+w_{2} \cdot \boldsymbol{j}\right) & =\left(z_{1} \cdot w_{1}-\beta \cdot z_{2} \cdot \overline{w_{2}}\right)+\left(z_{1} \cdot w_{2}+z_{2} \cdot \overline{w_{1}}\right) \cdot \boldsymbol{j}
\end{aligned}
$$

Megmutatható, hogy ha $w_{1} \in \mathbb{C}_{\alpha}$, akkor érvényes a

$$
\boldsymbol{j} \cdot w_{1}=\overline{w_{1}} \cdot \boldsymbol{j}
$$

összefüggés, amelynek speciális eseteként

$$
\boldsymbol{j} \cdot \boldsymbol{i}=-\boldsymbol{i} \cdot \boldsymbol{j}
$$


adódik.

Ha $z_{1}=a+b \cdot \boldsymbol{i}, z_{2}=c+d \cdot \boldsymbol{i} \in \mathbb{C}_{\alpha}$ és $q=z_{1}+z_{2} \cdot \boldsymbol{j} \in \mathbb{H}_{\alpha \beta}$, akkor a $q$ általánosított kvaternió felírható a $q=a+b \cdot \boldsymbol{i}+c \cdot \boldsymbol{j}+d \cdot \boldsymbol{i} \cdot \boldsymbol{j}$ alakban, s bevezetve a $\boldsymbol{k}:=\boldsymbol{i} \cdot \boldsymbol{j}$ jelölést minden $q \in \mathbb{H}_{\alpha \beta}$ előállítható a

$$
q=a \cdot \mathbf{1}+b \cdot \boldsymbol{i}+c \cdot \boldsymbol{j}+d \cdot \boldsymbol{k}
$$

alakban, amelyet az általánosított kvaternió valós algebrai alakjának hívjuk, az $\mathbf{1}, \boldsymbol{i}, \boldsymbol{j}, \boldsymbol{k} \in$ $\mathbb{H}_{\alpha \beta}$ elemeket pedig általánosított kvaternióegységeknek nevezzük.

A kvaternióegységek Cayley-féle szorzótáblája:

\begin{tabular}{|c|c|c|c|c||}
\hline & $\mathbf{1}$ & $\boldsymbol{i}$ & $\boldsymbol{j}$ & $\boldsymbol{k}$ \\
\hline $\mathbf{1}$ & $\mathbf{1}$ & $\boldsymbol{i}$ & $\boldsymbol{j}$ & $\boldsymbol{k}$ \\
\hline $\boldsymbol{i}$ & $\boldsymbol{i}$ & $-\alpha$ & $\boldsymbol{k}$ & $-\alpha \cdot \boldsymbol{j}$ \\
\hline $\boldsymbol{j}$ & $\boldsymbol{j}$ & $-\boldsymbol{k}$ & $-\beta$ & $\beta \cdot \boldsymbol{i}$ \\
\hline $\boldsymbol{k}$ & $\boldsymbol{k}$ & $\alpha \cdot \boldsymbol{j}$ & $-\beta \cdot \boldsymbol{i}$ & $-\alpha \cdot \beta$ \\
\hline
\end{tabular}

Az általánosított kvaterniók valós algebrai alakjával a következő számolási szabályok alapján dolgozhatunk:

$$
\begin{gathered}
r \cdot(a+b \cdot \boldsymbol{i}+c \cdot \boldsymbol{j}+d \cdot \boldsymbol{k})=(r \cdot a)+(r \cdot b) \cdot \boldsymbol{i}+(r \cdot c) \cdot \boldsymbol{j}+(r \cdot d) \cdot \boldsymbol{k} \\
(a+b \cdot \boldsymbol{i}+c \cdot \boldsymbol{j}+d \cdot \boldsymbol{k})+\left(a^{\prime}+b^{\prime} \cdot \boldsymbol{i}+c^{\prime} \cdot \boldsymbol{j}+d^{\prime} \cdot \boldsymbol{k}\right)= \\
=\left(a+a^{\prime}\right)+\left(b+b^{\prime}\right) \cdot \boldsymbol{i}+\left(c+c^{\prime}\right) \cdot \boldsymbol{j}+\left(d+d^{\prime}\right) \cdot \boldsymbol{k} \\
(a+b \cdot \boldsymbol{i}+c \cdot \boldsymbol{j}+d \cdot \boldsymbol{k}) \cdot\left(a^{\prime}+b^{\prime} \cdot \boldsymbol{i}+c^{\prime} \cdot \boldsymbol{j}+d^{\prime} \cdot \boldsymbol{k}\right)= \\
=\left(a \cdot a^{\prime}-\alpha \cdot b \cdot b^{\prime}-\beta \cdot c \cdot c^{\prime}-\alpha \cdot \beta \cdot d \cdot d^{\prime}\right)+ \\
+\left(a \cdot b^{\prime}+b \cdot a^{\prime}+\beta \cdot c \cdot d^{\prime}-\beta \cdot d \cdot c^{\prime}\right) \cdot \boldsymbol{i}+ \\
+\left(a \cdot c^{\prime}-\alpha \cdot b \cdot d^{\prime}+c \cdot a^{\prime}+\alpha \cdot d \cdot b^{\prime}\right) \cdot \boldsymbol{j}+ \\
+\left(a \cdot d^{\prime}+b \cdot c^{\prime}-c \cdot b^{\prime}+d \cdot a^{\prime}\right) \cdot \boldsymbol{k},
\end{gathered}
$$

ahol $r \in \mathbb{R}, a+b \cdot \boldsymbol{i}+c \cdot \boldsymbol{j}+d \cdot \boldsymbol{k}, a^{\prime}+b^{\prime} \cdot \boldsymbol{i}+c^{\prime} \cdot \boldsymbol{j}+d^{\prime} \cdot \boldsymbol{k} \in \mathbb{H}_{\alpha \beta}$.

A $q=z_{1}+z_{2} \cdot \boldsymbol{j} \in \mathbb{H}_{\alpha \beta}$ konjugáltján a $\bar{q}:=\overline{z_{1}}-z_{2} \cdot \boldsymbol{j} \in \mathbb{H}_{\alpha \beta}$ számot értjük. A konjugálást az alábbi tulajdonságok jellemzik: (a) $\overline{\bar{q}}=q$ involutív, b) $\bar{r} \cdot q=r \cdot \bar{q}$ homogén, (c) $\overline{q+q^{\prime}}=\bar{q}+\bar{q}^{\prime} \quad$ additív, $\quad$ (d) $\quad \overline{q \cdot q^{\prime}}=\overline{q^{\prime}} \cdot \bar{q} \quad$ anti-multiplikatív, (e) $q \cdot \bar{q}=\bar{q} \cdot q=a^{2}+\alpha \cdot b^{2}+\beta \cdot c^{2}+\alpha \cdot \beta \cdot d^{2} \in \mathbb{R} \quad, \quad$ ahol $\quad r \in \mathbb{R}, z_{1}=a+b \cdot \boldsymbol{i}$, $z_{2}=c+d \cdot \boldsymbol{i} \in \mathbb{C}_{\alpha}$ és $q=z_{1}+z_{2} \cdot \boldsymbol{j} \in \mathbb{H}_{\alpha \beta}$.

A $q=z_{1}+z_{2} \cdot \boldsymbol{j} \in \mathbb{H}_{\alpha \beta}$ elem normáján a $N(q)=q \cdot \bar{q} \in \mathbb{R}$ számot értjük, amelyre teljesülnek az alábbi összefüggések: (a) minden $q, q^{\prime} \in \mathbb{H}_{\alpha \beta}$ esetén $N\left(q \cdot q^{\prime}\right)=N(q) \cdot N\left(q^{\prime}\right)$, (b) $q \in \mathbb{H}_{\alpha \beta}$ elem invertálható akkor és csakis akkor, ha $N(q) \neq 0$, (c) ha $p, q \in \mathbb{H}_{\alpha \beta}$ invertálható elemek, akkor $p \cdot q \in \mathbb{H}_{\alpha \beta}$ is invertálható és $(p \cdot q)^{-1}=q^{-1} \cdot p^{-1}$.

A $q=a+b \cdot \boldsymbol{i}+\mathrm{c} \cdot \boldsymbol{j}+d \cdot \boldsymbol{k}, q^{\prime}=a^{\prime}+b^{\prime} \cdot \boldsymbol{i}+c^{\prime} \cdot \boldsymbol{j}+d^{\prime} \cdot \boldsymbol{k} \in \mathbb{H}_{\alpha \beta}$ elempár skaláris szorzatán a $\left\langle q, q^{\prime}\right\rangle:=a \cdot a^{\prime}+\alpha \cdot b \cdot b^{\prime}+\beta \cdot c \cdot c^{\prime}+\alpha \cdot \beta \cdot d \cdot d^{\prime} \in \mathbb{R}$ számot értjük. A skaláris szorzat egy szimmetrikus bilineáris leképezés, ebből a norma az $N(q)=\langle q, q\rangle$ alapján származtatható.

A $q=a+b \cdot \boldsymbol{i}+c \cdot \boldsymbol{j}+d \cdot \boldsymbol{k} \in \mathbb{H}_{\alpha \beta}$ általánosított kvaterniók reprezentálhatók az 


$$
A=\left(\begin{array}{cccc}
a & b & c & d \\
-\alpha \cdot b & a & -\alpha \cdot d & c \\
-\beta \cdot c & \beta \cdot d & a & -b \\
-\alpha \cdot \beta \cdot d & -\beta \cdot c & \alpha \cdot b & a
\end{array}\right) \in M_{4}(\mathbb{R})
$$

alakú mártixok $M_{4}^{\mathbb{H}}(\mathbb{R})$ halmazával, mivel a

$$
G: \mathbb{H}_{\alpha \beta} \rightarrow M_{4}^{\mathbb{H}}(\mathbb{R}), a+b \cdot \boldsymbol{i}+c \cdot \boldsymbol{j}+d \cdot \boldsymbol{k} \mapsto\left(\begin{array}{cccc}
a & b & c & d \\
-\alpha \cdot b & a & -\alpha \cdot d & c \\
-\beta \cdot c & \beta \cdot d & a & -b \\
-\alpha \cdot \beta \cdot d & -\beta \cdot c & \alpha \cdot b & a
\end{array}\right)
$$

leképezés egy algebra-izomorfizmus, érvényes továbbá az

$$
N^{2}(q)=\operatorname{det}\left(\begin{array}{clcc}
a & b & c & d \\
-\alpha \cdot b & a & -\alpha \cdot d & c \\
-\beta \cdot c & \beta \cdot d & a & -b \\
-\alpha \cdot \beta \cdot d & -\beta \cdot c & \alpha \cdot b & a
\end{array}\right)
$$

összefüggés.

Minden $\alpha, \beta \in \mathbb{R}$ esetén a $\mathbb{H}_{\alpha \beta}$ struktúra összeadása és skalárral való szorzása (10) és (11), továbbá (19) és (20) szerint azonos, tehát az összeg és a skalárszoros is független az $\alpha$ és $\beta$ paraméterek megválasztásától. A $\mathbb{H}_{\alpha \beta}$ struktúrák közötti eltérés a szorzásban van, amelyet a (12) és (21) szerint az $\alpha, \beta \in \mathbb{R}$ paraméterpár határoz meg. E szorzást viszont az összeadásra vonatkozó disztributivitás szabálya miatt egyértelműen meghatározza az általánosított kvaternióegységek Cayley-féle szorzótáblája.

A $\quad \tau: a+b \cdot \boldsymbol{i}+c \cdot \boldsymbol{j}+d \cdot \boldsymbol{k} \mapsto a+c \cdot \boldsymbol{i}+b \cdot \boldsymbol{j}+d \cdot \boldsymbol{k}$ transzpozíciós leképezés, valamint a $\kappa: a+b \cdot \boldsymbol{i}+c \cdot \boldsymbol{j}+d \cdot \boldsymbol{k} \mapsto a-b \cdot \boldsymbol{i}-c \cdot \boldsymbol{j}-d \cdot \boldsymbol{k}$ konjugálási leképezés is algebra-izomorfizmusok, amelyek $\kappa \circ \tau$ kompozíciója a $\mathbb{H}_{\alpha \beta}$ kvaternióegységeinek szorzótábláját éppen a $\mathbb{H}_{\beta \alpha}$ kvaternióegységeinek szorzótáblájába viszi át. Ezért $\mathbb{H}_{\beta \alpha}$ algebra izomorf a $\mathbb{H}_{\alpha \beta}$ algebrával.

Legyen $E:=\{-1,0,1\}$. Láttuk, hogy $\mathbb{C}_{\alpha}$ mindhárom alaptípusánál $\alpha \in E$ teljesül. Ha $\beta \in E$ is fennáll, akkor közvetlenül belátható, $\alpha \cdot \beta \in E$ is teljesül. Ekkor viszont az általánosított kvaternióegységek négyzeteire $\mathbf{1}^{2}=1, \boldsymbol{i}^{2}=-\alpha, \boldsymbol{j}^{2}=-\beta, \boldsymbol{k}^{2}=-\alpha \cdot \beta$ miatt $\mathbf{1}^{2}, \boldsymbol{i}^{2}, \boldsymbol{j}^{2}, \boldsymbol{k}^{2} \in E$ is teljesül, vagyis a kvaternióegységek szerepe szimmetrikus. Ezért az $\alpha, \beta \in E$ esetben a $\mathbb{H}_{\alpha \beta}$ általánosított kvaternióalgebrát szimmetrikusnak nevezzük, amelyet az $(\alpha, \beta)$ értékpárjainak megfelelően a következő táblázatba rendezhetjük:

\begin{tabular}{||c|c|c|}
\hline$(1,1)$ & $(1,-1)$ & $(1,0)$ \\
\hline$(-1,1)$ & $(-1,-1)$ & $(-1,0)$ \\
\hline$(0,1)$ & $(0,-1)$ & $(0,0)$ \\
\hline
\end{tabular}

E 9 struktúra közül a $\mathbb{H}_{\alpha \beta}$ és $\mathbb{H}_{\beta \alpha}$ izomorf volta miatt elegendő pl. a felső trianguláris 6 struktúrát tekinteni: 


\begin{tabular}{|c|c|c|}
\hline$(1,1)$ & $(1,-1)$ & $(1,0)$ \\
\hline & $(-1,-1)$ & $(-1,0)$ \\
\hline & & $(0,0)$ \\
\hline
\end{tabular}

E struktúrák közül 5 ismert, amelyek a táblázat első sorában és harmadik oszlopában szerepelnek. Ezek éppen a $\mathbb{H}_{\alpha \beta}$ általánosított kvaternióalgebrákra korábban példaként említett $\mathbb{H}, \mathbb{H}^{\prime}, \mathbb{H}^{\circ}, \mathbb{H}^{\prime \circ}$ és $\mathbb{H}^{\circ \circ}$ struktúrák.

Az $(\alpha, \beta)=(-1,-1)$ paraméterpárral rendelkező $\mathbb{H}_{\alpha \beta}$ 6. struktúrában az elemeket a (19) és (20) összefüggés szerint kell skalárral szorozni és összeadni, szorozni pedig a (21) szerint az $\alpha=\beta=-1$ helyettesítéssel. Ekkor a normát a $N(q)=a^{2}-b^{2}-c^{2}+d^{2}$ alapján, a skaláris szorzatot a $\left\langle q, q^{\prime}\right\rangle=a \cdot a^{\prime}-b \cdot b^{\prime}-c \cdot c^{\prime}+d \cdot d^{\prime}$ összefüggéssel számolhatjuk, végül e struktúrában szereplő kvaterniókat a

$$
\left(\begin{array}{cccc}
a & b & c & d \\
b & a & d & c \\
c & -d & a & -b \\
-d & c & -b & a
\end{array}\right) \in M_{4}(\mathbb{R})
$$

alakú mátrixok reprezentálják.

\section{Befejezés}

Az előző részben az általánosított kvaternióalgebrák egy, az általánosított komplex számok algebrájára támaszkodó felépítését mutattuk be. Ennek kapcsán vezettük be és határoztuk meg a szimmetrikus általánosított kvaternióalgebrákat, s utaltunk egy, korábban a szakirodalomban nem vizsgált típusára.

Az általánosított kvaternióalgebrák más tárgyalásával találkozhatunk JAFARI (2016) és JAFARI - YAYLI (2015), valamint PIERCE (1982) munkáiban is.

A dolgozatban bemutatott felépítés folytatható és felépíthető e módszerrel a Cayley-féle oktoniók algebrája is, amelynek vizsgálatával a jövőben kívánunk foglalkozni.

\section{Irodalomjegyzék}

[1] Jafari, M., Quaternion Algebra and Its Application: An Overview, Intern. Journ. of Theoret. and Appl. Math. 2(2), (2016) 79-85. doi:10.11648/j.ijtam.20160202.18

[5] Jafari, M. - Yayli, Y., Generalized Quaternions and Their Algebraic Properties. Commun. Fac. Univ. Ank. Ser. A1, 64(1), (2015) 15-27. doi:10.1501/Commua1_0000000724

[6] Hamilton, W. R., On Conjugate functions, or algebraic Couples. British Association Report, Edinburg, (1834) 519-523.

[7] Hamilton, W. R., On a new Species of Imaginary quantities connected with a Theory of quaternions. Proceedings of the Royal Irish Academy 2, (1944) 424-434.

[8] Pierce, R. S., Associative Algebras. Springer-Verlag, New York, Heidelberg, Berlin, 1982. doi:10.1007/978-1-4757-0163-0

[9] Rosenfeld, B., Geometry of Lie groups. Kluwer Academic Publishers, Netherlands, 1997. doi:10.1007/978-1-4757-5325-7

[10] Ward, J. P., Quaternions and Cayley Numbers. Springer Science, Bussines Media B.V, 1997. doi:10.1007/978-94-011-5768-1 